Publicación semestral. ISSN 2215-4906

Volumen 80 - Número 2

Enero - Junio 2021

\title{
Entre el mercado global del arte contemporáneo y la muerte: la obra de Teresa Margolles
}

\author{
Between Global Market of Contemporary Art and Death: \\ the Work of Teresa Margolles
}

Sindy Mora Solano

\section{(c) (i) $($ )}

Esta obra está bajo una licencia Creative Commons

Reconocimiento-No comercial-Sin Obra Derivada 
Dossier

\title{
Entre el mercado global del arte contemporáneo y la muerte: la obra de Teresa Margolles
}

\author{
Between Global Market of Contemporary Art and Death: \\ the Work of Teresa Margolles
}

\author{
Sindy Mora Solano ${ }^{1}$ \\ Universidad de Costa Rica \\ Costa Rica
}

Recibido: 28 de junio de 2019 Aprobado: 30 de diciembre de 2019

\begin{abstract}
Resumen
En este artículo se analiza la obra de la artista mexicana Teresa Margolles y se expone la tesis de que su trabajo se ha posicionado en el mercado global del arte, promovido por la paradoja permisiva de la institucionalidad del arte contemporáneo. Mediante este mecanismo, Margolles ha exportado, desde la periferia hasta el centro, un arte que enfatiza en las imágenes de violencia y de muerte, además de convertirlas en objetos exóticos de exposición en museos europeos y estadounidenses. En el texto, se analizan tres de sus obras: ¿De qué otra cosa podríamos hablar? (2009), La Promesa (2012) y El Testigo (2014).

Palabras clave: arte contemporáneo; mercado global del arte; muerte; Teresa Margolles

\section{Abstract}

This paper analyzed the work of the Mexican artist Teresa Margolles. It exposes the thesis that her work has been positioned in the global art market, promoted by the "permissive paradox" of the institutionality of contemporary art. Through this mechanism, Margolles has exported, from the periphery to the center, an art that emphasizes images of violence and death, transforming violence and death into exotic objects of exhibition in European and American museums. In the paper are analyzed ¿De qué otra cosa podríamos hablar? (2009), La Promesa (2012) and El Testigo (2014).
\end{abstract}

Keywords: contemporary art; global art market; death; Teresa Margolles

1 Investigadora en el Instituto de Investigaciones Sociales, Universidad de Costa Rica (UCR). Máster en Derechos Humanos y Educación para la Paz. ORCID: 0000-0001-6784-5532. Correo electrónico: sindy.mora@ucr.ac.cr

ESCENA. Revista de las artes, 2021, Vol. 80, Núm. 2, pp. 198-220 ISSN 2215-4906 


\section{Introducción}

Teresa Margolles es, actualmente, una de las máximas exponentes del arte contemporáneo, con un amplio reconocimiento mundial (Kilchmann, 2018). Esta artista nació en el año 1963, en Culiacán, estado de Sinaloa, México. Estudió Arte en la Dirección de Fomento a la Cultura Regional del Estado de Sinaloa (DIFOCUR); se diplomó en Medicina Forense en el Servicio Mexicano Forense en el año 1990 y en Ciencias de la Comunicación en la Universidad Nacional Autónoma de México (UNAM) en el año 1995. En 1990 fundó el colectivo Servicio Médico Forense (SEMEFO), grupo con el que participó entre 1990 y 1999. Este colectivo se dedicó al performance y a las instalaciones realizadas con fluidos corporales, partes de cuerpos y cadáveres. En el año 2000, Teresa Margolles se separó del colectivo SEMEFO e inició su trabajo como artista individual.

En este texto se analiza la obra de Teresa Margolles a la luz de los ejes centrales del debate en torno al arte contemporáneo. Además, se señala que su producción artística se ha posicionado en el mercado global del arte, promovida por la "paradoja permisiva" de la institucionalidad del arte contemporáneo, tesis que se expone Heinich, 2017. Mediante este mecanismo, Margolles ha exportado un arte en el que se enfatizan las imágenes de violencia y de muerte (Didi-Huberman, 2018; Speranza, 2012), las cuales se exponen como objetos exóticos en museos europeos y estadounidenses (Campiglia, 2013).

En el primer apartado de este artículo, se discute sobre las dinámicas del campo artístico, la institucionalización del arte contemporáneo y la noción de contemporaneidad. En el segundo apartado, se estudian las exposiciones colectivas e individuales de Teresa Margolles, con el fin de dar cuenta de su posicionamiento como una artista en el campo global del arte. Asimismo, se exponen los principales ejes de tres de sus obras, las cuales se titulan: ¿De qué otra cosa podríamos hablar?, presentada en el año 2009; La Promesa, del año 2012, y El Testigo, del año 2014. El estudio concluye, en un tercer apartado titulado "Reflexiones finales", con las principales críticas hechas a la obra de Margolles y el análisis de su trabajo artístico a partir de la teoría expuesta.

\section{Reflexiones teóricas}

En este artículo se parte de reflexiones teóricas que permiten posicionar la obra de Teresa Margolles en el marco del paradigma del arte contemporáneo, según lo propuesto por la socióloga francesa Nathalie Heinich (2002; 2017). Como señala esta autora, siguiendo a Thomas Kuhn, a partir de los años setenta del siglo pasado, se configuró un nuevo 
paradigma artístico, cuyas rupturas fueron más allá del ámbito estilístico o estético, ya que con este nuevo paradigma se instauró, también, "una nueva relación entre el arte y la realidad, sus objetos y sus imágenes" (Heinich, 2017, p. 33).

En el marco de la coexistencia entre el paradigma del arte moderno y el del arte contemporáneo, las expresiones de este último aparecieron como anomalías del arte moderno y sus reglas. Es decir, como parte de "una concepción del arte que no respeta esos cánones, que se emancipa del género abarcador que constituía la pintura narrativa y, de manera general, hace caso omiso de la jerarquía de los géneros" (Heinich, 2017, p. 50). Esto implicó una reorganización del campo artístico respecto al paradigma del arte moderno, con el surgimiento de nuevos especialistas e intermediarios en esta área, con el advenimiento, también, de sus críticos y detractores, con la instauración de nuevos mecanismos para otorgar reconocimiento al arte y con las correspondientes transformaciones en el mercado global del arte.

Junto a estas transformaciones, se establecieron nuevos límites en el mundo del arte. Como señala Heinich (2017), el arte contemporáneo se basa en la "paradoja permisiva", tesis que propone que la institucionalidad que sostiene y promueve el arte contemporáneo suscita constantemente la ruptura de los límites y la radicalización de las propuestas artísticas, las cuales son avaladas e incorporadas en la institucionalidad artística, invalidando la idea de lo radical. En palabras de la autora:

el arte contemporáneo se basa en la transgresión de los límites del arte tal como el sentido común los percibe; y que las instituciones, al aceptar e incluso fomentar esas transgresiones, propician una "paradoja permisiva" que lleva a una radicalización de las propuestas artísticas en una escalada de apuestas que no deja de expandir los límites del arte (Heinich, 2017, p. 59).

De esta forma, un ámbito en el que se puede observar la redefinición de los límites en el paradigma del arte contemporáneo es en la concepción de lo bello en el arte, ya que el criterio de la belleza ha sido cuestionado por este paradigma. Es decir, la belleza ya no es el mecanismo articulador de las expresiones artísticas. En este sentido, lo abyecto, lo grotesco, lo siniestro, lo sucio o lo feo son parte fundamental de este paradigma. Tal y como lo ha señalado Marc Jiménez (2010), este es un eje central de la polémica en el arte contemporáneo, ya que la crítica ha posicionado la idea de que cualquier cosa puede ser entendida como arte, incluso lo no bello. Como señala este autor, la crítica de "'cualquier cosa' que tan a menudo se les reprochaba a las prácticas contemporáneas excluía, por definición toda 
referencia a un ideal de belleza" (Jiménez, 2010, p. 144). Por ello, para este autor, la querella respecto al arte contemporáneo reside, justamente, "en nuestras representaciones del arte y de su lugar en la cultura" (Jiménez, 2010, p. 167), en donde, para decirlo con palabras de Heinich, lo bello se entiende como un elemento central del paradigma moderno, en disputa con el paradigma del arte contemporáneo.

Otra de las aristas en las que se puede observar rupturas entre los límites del arte es en el papel que tiene el mercado en la creación de circuitos de reconocimiento global del arte. De esta forma, según Heinich, en el arte contemporáneo, figuras como las de los intermediarios especializados han jugado un papel fundamental en la reconfiguración de un mercado global del arte, caracterizado por "la creación de nuevas segmentaciones, nuevas fronteras, nuevas redes de circulación de objetos y personas" (Heinich, 2017, p. 43).

En ese sentido, es importante recordar que el sociólogo francés Pierre Bourdieu ya había señalado que la figura del artista se encontraba definida por el reconocimiento obtenido en el campo artístico, ante la mirada legitimadora de otros artistas (Bourdieu, 2010). Este autor entiende el campo artístico como un escenario en el que artistas, curadores y críticos del campo "discuten y luchan a propósito del arte que unos producen y los otros comentan" (Bourdieu, 2010, p. 31). Es decir, "el artista es aquel de quien los artistas dicen que es un artista. O bien: el artista es aquel cuya existencia en cuanto artista está en juego en ese juego que llamo campo artístico" (Bourdieu, 2010, p. 25), hoy por hoy, en un escenario global.

De esta manera, en el escenario global del arte contemporáneo es fundamental analizar qué tipo de arte es reconocido globalmente, qué sistema burocrático o institucional otorga el reconocimiento y mediante cuáles mecanismos este se concede. Ya que, como también ha señalado Arthur Danto, "el arte puede ser lo que quieran los artistas y los patrocinadores” (Danto, 1997, p. 58). Esto plantea una reflexión fundamental sobre la figura del museo en un escenario global del arte (Didi-Huberman, 2017; Rivera Cusicanqui \& El Colectivo, 2010), así como la gestión institucional de los gustos del público (Bourdieu, 2013).

Ahora bien, más allá de la dimensión institucional del arte, ¿qué se puede decir del arte contemporáneo respecto a su tiempo?, ¿qué es lo contemporáneo? En el texto Desnudez, Giorgio Agamben (2011) ha señalado que la contemporaneidad implica una forma de mirar el mundo para dar cuenta no solo de sus luces, sino también de su oscuridad. Por ello, el artista tiene una relación singular con el tiempo: este puede ser capaz de tomar distancia de su tiempo, desentroncarse de él, para entroncarse nuevamente en él, mirando 
algo del tiempo que los otros no tienen la capacidad de mirar. De esta manera, en palabras de Agamben:

contemporáneo es aquel que mantiene la mirada fija en su tiempo, para percibir, no sus luces, sino su oscuridad. Todos los tiempos son, para quien experimenta su contemporaneidad, oscuros. Contemporáneo es, justamente, aquel que sabe ver esa oscuridad, aquel que está en condiciones de escribir humedeciendo la pluma en la tiniebla del presente (Agamben, 2011, p. 21).

En ese sentido, lo abyecto y lo grotesco como formas de arte dan cuenta y expresan lo que el presente contiene, haciendo del artista contemporáneo un portavoz de los conflictos y los dolores de su época. Marc Jiménez posiciona la crítica a las obras del arte contemporáneo en una dimensión que permite visualizar que, si bien el arte contemporáneo ha cometido algunos "excesos", estos no son mayores y, por el contrario, forman parte de la oscuridad que caracteriza la época. De esta manera, el arte contemporáneo puede permitir la formulación de preguntas en torno a lo que ruboriza o escandaliza más a una sociedad: los procesos ocursos del presente o el arte que los problematiza. De acuerdo con Jiménez: "el arte actual se ha convertido en una ficción realista, aunque, a pesar de sus excesos, sea ampliamente superado, en lo espectacular, lo escandaloso o lo horrible, por el realismo a menudo crudo y violento de la 'verdadera' realidad" (Jiménez, 2010, p. 260).

Para finalizar esta reflexión es central recuperar la visión del arte contemporáneo, según los mapas y las rutas territoriales que este permite reconstruir. Como señala Graciela Speranza, es fundamental plantear preguntas sobre el arte latinoamericano en un mercado globalizado, elemento también subrayado por Nathalie Heinich, con el fin de comprender las formas de

figurar el mundo en cartografías imaginarias, registrar nuevas experiencias psicogeográficas en las ciudades, abrirse a redes de relaciones flexibles o clausurarse en esferas incomunicadas, revelar supervivencias en la historia del arte, repensar la identidad, el territorio, las raíces, la lengua y la patria (Speranza, 2012, p. 17).

Estas preguntas adquieren sentido en un escenario en donde el colonialismo interno se conjuga con el colonialismo externo (Schwartzberg, 2010) y, en muchas ocasiones, América Latina termina aportando la materia prima de lo que en Europa es considerado arte (Geidel, 2010). Siguiendo a Georges Didi-Huberman, en su texto Pueblos expuestos, pueblos figurantes (2018), la obra de Teresa Margolles puede analizarse indagando 
en torno a las formas de representación y de exposición de los pueblos latinoamericanos en el mercado global del arte. En esta configuración de mapas y rutas globales de las que habla Speranza, ¿los pueblos latinoamericanos se encuentran sobreexpuestos mediante imágenes estereotipadas o aparecen subexpuestos mediante imágenes incompletas que los hacen aparecer como pueblos sin rostro?, ¿de qué humanidad habla el arte contemporáneo? Y, en el caso de la obra de Teresa Margolles, ¿de qué humanidad hablan los fluidos corporales, los cadáveres y la muerte?

\section{La obra de Teresa Margolles}

Durante el siglo XX e inicios del siglo XXI, el arte mexicano se caracterizó por su significativa representación y problematización de la violencia política (Barbosa, 2018; Dieguez, 2018). Al menos tres etapas han sido identificadas en este proceso: la primera de ellas refiere al arte revolucionario de los muralistas mexicanos de inicios del siglo XX; la segunda se ubica en la década de 1970, que tuvo como punto de partida la violencia de Estado, inaugurada con el asesinato de la Plaza de Tlatelolco, de 1968, proceso que fue acompañado por el surgimiento de diversos colectivos artísticos que denunciaron el terror de Estado. En el último periodo, la producción artística ha denunciado la violencia vinculada a la guerra contra el narcotráfico, declarada por el presidente Felipe Calderón (2006- 2012), etapa en la que se posiciona la obra de Teresa Margolles, tanto como la de otros artistas en la literatura y la pintura (Barbosa, 2018).

En este escenario, Teresa Margolles ha obtenido un amplio reconocimiento global en el campo artístico, como se puede observar en la información que se presenta en el cuadro 1. En este, se sistematizan las exposiciones colectivas e individuales de la artista, de acuerdo con el país en el que se han realizado dichas exposiciones. Esta información ha sido procesada a partir del trabajo realizado por Peter Kilchmann, en el que se recopila información de todas las exposiciones realizadas por la artista (Kilchmann, 2018). De acuerdo con la información sistematizada, Teresa Margolles ha participado en 278 exposiciones colectivas y en 67 exposiciones de carácter individual, entre 1995 y 2018. En el caso de las exposiciones colectivas, 141 han sido realizadas en Europa, lo que corresponde al 40,9\% de este tipo de presentaciones. Cien de estas exposiciones fueron realizadas en América del Norte, principalmente en Estados Unidos (54 exhibiciones) y México (39 exhibiciones). En términos porcentuales, esto significa que $15,7 \%$ de las exposiciones colectivas se realizaron en Estados Unidos y 11,3\% en México. En América del Sur, la artista realizó 17 exposiciones y en América Central únicamente 6.

ESCENA. Revista de las artes, 2021, Vol. 80, Núm. 2 (enero-junio), pp. 198-220 
En cuanto a las exposiciones individuales, que en total fueron 67, un 51\%, es decir, 34 de las exposiciones, se realizaron en Europa, siendo España y Suiza los países en los que Margolles ha realizado un mayor número de presentaciones, con 8 y 7 exposiciones, respectivamente. Teresa Margolles expuso su obra en América del Norte en 26 ocasiones, con 16 exposiciones en México y 9 en Estados Unidos. Como se puede observar, Teresa Margolles es una artista reconocida como tal frente a un público global, fundamentalmente, europeo. De las 345 exposiciones colectivas e individuales realizadas por la artista, solamente un 16\% han sido realizadas en México; es decir, el $84 \%$ restante de exposiciones se han exportado, ya que han sido realizadas fuera de dicho país. En el mapa 1, se sistematiza la información expuesta: los puntos azules corresponden a las exposiciones individuales y los puntos rojos a las colectivas. Como se observa, en el mapa destacan tres espacios en donde la artista de origen mexicano ha expuesto su obra: Europa, Estados Unidos y México.

\begin{tabular}{|c|c|c|c|c|c|c|}
\hline \multicolumn{7}{|c|}{$\begin{array}{l}\text { Cuadro } 1 \\
\begin{array}{l}\text { Exposiciones individuales y colectivas de Teresa Margolles, entre 1995-2018, según } \\
\text { continente, subcontinente y país en que se realizó la exposición }\end{array}\end{array}$} \\
\hline $\begin{array}{l}\text { Continente / } \\
\text { subcontinente y país }\end{array}$ & $\begin{array}{l}\text { Exposiciones } \\
\text { colectivas }\end{array}$ & $\%$ & $\begin{array}{l}\text { Exposiciones } \\
\text { individuales }\end{array}$ & $\%$ & $\begin{array}{c}\text { Total de } \\
\text { exposiciones }\end{array}$ & $\%$ \\
\hline Europa & 141 & $40,9 \%$ & 34 & $9,9 \%$ & 175 & $50,7 \%$ \\
\hline España & 30 & $8,7 \%$ & 8 & $2,3 \%$ & 38 & $11,0 \%$ \\
\hline Alemania & 21 & $6,1 \%$ & 4 & $1,2 \%$ & 25 & $7,2 \%$ \\
\hline Suiza & 15 & $4,3 \%$ & 7 & $2,0 \%$ & 22 & $6,4 \%$ \\
\hline Italia & 15 & $4,3 \%$ & 4 & $1,2 \%$ & 19 & $5,5 \%$ \\
\hline Francia & 12 & $3,5 \%$ & 3 & $0,9 \%$ & 15 & $4,3 \%$ \\
\hline Inglaterra & 11 & $3,2 \%$ & & $0,0 \%$ & 11 & $3,2 \%$ \\
\hline Bélgica & 6 & $1,7 \%$ & 1 & $0,3 \%$ & 7 & $2,0 \%$ \\
\hline Polonia & 5 & $1,4 \%$ & & $0,0 \%$ & 5 & $1,4 \%$ \\
\hline Austria & 5 & $1,4 \%$ & 3 & $0,9 \%$ & 8 & $2,3 \%$ \\
\hline Holanda & 4 & $1,2 \%$ & 2 & $0,6 \%$ & 6 & $1,7 \%$ \\
\hline Irlanda & 3 & $0,9 \%$ & & $0,0 \%$ & 3 & $0,9 \%$ \\
\hline Suecia & 3 & $0,9 \%$ & & $0,0 \%$ & 3 & $0,9 \%$ \\
\hline Eslovenia & 2 & $0,6 \%$ & & $0,0 \%$ & 2 & $0,6 \%$ \\
\hline
\end{tabular}

ESCENA. Revista de las artes, 2021, Vol. 80, Núm. 2 (enero-junio), pp.198-220 
Entre el mercado global del arte contemporáneo y

Dossier

la muerte: la obra de Teresa Margolles

\begin{tabular}{|c|c|c|c|c|c|c|}
\hline \multicolumn{7}{|c|}{ 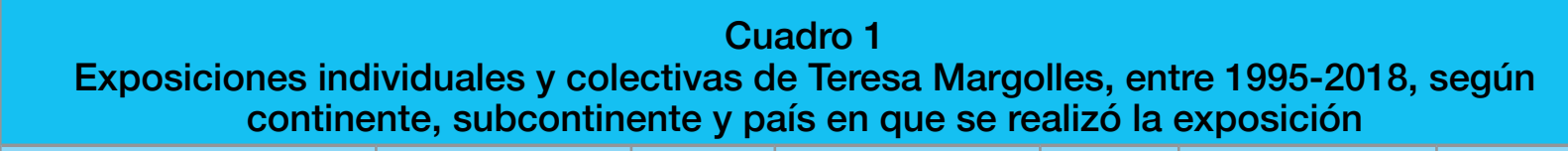 } \\
\hline $\begin{array}{l}\text { Continente / } \\
\text { subcontinente y país }\end{array}$ & $\begin{array}{c}\text { Exposiciones } \\
\text { colectivas }\end{array}$ & $\%$ & $\begin{array}{l}\text { Exposiciones } \\
\text { individuales }\end{array}$ & $\%$ & $\begin{array}{l}\text { Total de } \\
\text { exposiciones }\end{array}$ & $\%$ \\
\hline República Checa & 2 & $0,6 \%$ & & $0,0 \%$ & 2 & $0,6 \%$ \\
\hline Grecia & 2 & $0,6 \%$ & & $0,0 \%$ & 2 & $0,6 \%$ \\
\hline Lituania & 1 & $0,3 \%$ & & $0,0 \%$ & 1 & $0,3 \%$ \\
\hline Hungría & 1 & $0,3 \%$ & & $0,0 \%$ & 1 & $0,3 \%$ \\
\hline Ucrania & 1 & $0,3 \%$ & & $0,0 \%$ & 1 & $0,3 \%$ \\
\hline Escocia & 1 & $0,3 \%$ & 1 & $0,3 \%$ & 2 & $0,6 \%$ \\
\hline Rusia & 1 & $0,3 \%$ & & $0,0 \%$ & 1 & $0,3 \%$ \\
\hline Croacia & & $0,0 \%$ & 1 & $0,3 \%$ & 1 & $0,3 \%$ \\
\hline América del Norte & 100 & $29,0 \%$ & 26 & $7,5 \%$ & 126 & $36,5 \%$ \\
\hline Estados Unidos & 54 & $15,7 \%$ & 9 & $2,6 \%$ & 63 & $18,3 \%$ \\
\hline México & 39 & $11,3 \%$ & 16 & $4,6 \%$ & 55 & $15,9 \%$ \\
\hline Canadá & 7 & $2,0 \%$ & 1 & $0,3 \%$ & 8 & $2,3 \%$ \\
\hline América del Sur & 17 & $4,9 \%$ & 5 & $1,4 \%$ & 22 & $6,4 \%$ \\
\hline Brasil & 7 & $2,0 \%$ & 3 & $0,9 \%$ & 10 & $2,9 \%$ \\
\hline Colombia & 4 & $1,2 \%$ & 1 & $0,3 \%$ & 5 & $1,4 \%$ \\
\hline Argentina & 2 & $0,6 \%$ & & $0,0 \%$ & 2 & $0,6 \%$ \\
\hline Uruguay & 1 & $0,3 \%$ & & $0,0 \%$ & 1 & $0,3 \%$ \\
\hline Ecuador & 1 & $0,3 \%$ & & $0,0 \%$ & 1 & $0,3 \%$ \\
\hline Chile & 1 & $0,3 \%$ & 1 & $0,3 \%$ & 2 & $0,6 \%$ \\
\hline Bolivia & 1 & $0,3 \%$ & & $0,0 \%$ & 1 & $0,3 \%$ \\
\hline América Central & 6 & $1,7 \%$ & 1 & $0,3 \%$ & 7 & $2,0 \%$ \\
\hline Guatemala & 2 & $0,6 \%$ & 1 & $0,3 \%$ & 3 & $0,9 \%$ \\
\hline Costa Rica & 2 & $0,6 \%$ & & $0,0 \%$ & 2 & $0,6 \%$ \\
\hline Panamá & 1 & $0,3 \%$ & & $0,0 \%$ & 1 & $0,3 \%$ \\
\hline
\end{tabular}

ESCENA. Revista de las artes, 2021, Vol. 80, Núm. 2 (enero-junio), pp. 198-220 


\section{Cuadro 1}

Exposiciones individuales y colectivas de Teresa Margolles, entre 1995-2018, según continente, subcontinente y país en que se realizó la exposición

\begin{tabular}{|l|c|c|c|c|c|c|}
\hline \multicolumn{1}{|c|}{$\begin{array}{c}\text { Continente / } \\
\text { subcontinente y país }\end{array}$} & $\begin{array}{c}\text { Exposiciones } \\
\text { colectivas }\end{array}$ & $\%$ & $\begin{array}{c}\text { Exposiciones } \\
\text { individuales }\end{array}$ & $\%$ & $\begin{array}{c}\text { Total de } \\
\text { exposiciones }\end{array}$ & $\%$ \\
\hline Nicaragua & 1 & $0,3 \%$ & & $0,0 \%$ & 1 & $0,3 \%$ \\
\hline Asia & 6 & $1,7 \%$ & 1 & $0,3 \%$ & 7 & $2,0 \%$ \\
\hline Israel & 2 & $0,6 \%$ & & $0,0 \%$ & 2 & $0,6 \%$ \\
\hline $\begin{array}{l}\text { Emiratos Árabes } \\
\text { Unidos }\end{array}$ & 1 & $0,3 \%$ & & $0,0 \%$ & 1 & $0,3 \%$ \\
\hline Japón & 1 & $0,3 \%$ & & $0,0 \%$ & 1 & $0,3 \%$ \\
\hline Corea del Sur & 1 & $0,3 \%$ & & $0,0 \%$ & 1 & $0,3 \%$ \\
\hline China & 1 & $0,3 \%$ & 1 & $0,3 \%$ & 2 & $0,6 \%$ \\
\hline Caribe & 1 & $1,2 \%$ & & $0,0 \%$ & 4 & $1,2 \%$ \\
\hline Puerto Rico & $0,9 \%$ & & $0,0 \%$ & 3 & $0,9 \%$ \\
\hline Cuba & 2 & $0,3 \%$ & & $0,0 \%$ & 1 & $0,3 \%$ \\
\hline Oceanía & 1 & $0,9 \%$ & & $0,0 \%$ & 3 & $0,9 \%$ \\
\hline Australia & 1 & $0,3 \%$ & & $0,0 \%$ & 2 & $0,6 \%$ \\
\hline Nueva Zelanda & 1 & $0,3 \%$ & & $0,0 \%$ & 1 & $0,3 \%$ \\
\hline América Latina & 278 & $80,6 \%$ & 67 & $19,4 \%$ & 345 & $100,0 \%$ \\
\hline América Latina & 1 & & $0,0 \%$ & 1 & $0,3 \%$ \\
\hline Total general & 1 & & & & \\
\hline
\end{tabular}

Fuente: Elaboración propia a partir de Kilchmann, 2018.

* No se identifica el país 
Entre el mercado global del arte contemporáneo y

Dossier

la muerte: la obra de Teresa Margolles

Imagen 1. Exposiciones individuales y colectivas de Teresa Margolles, entre 1995-2018, según continente, subcontinente y país en que se realizó la exposición

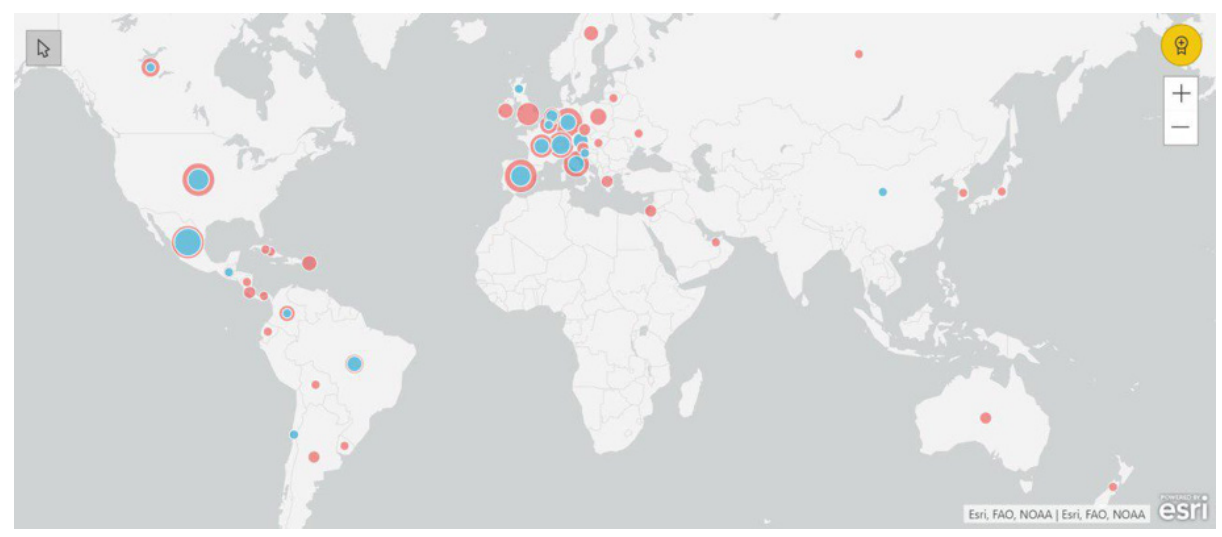

Fuente: Elaboración propia a partir de Kilchmann, 2018.

Seguidamente, se presenta un análisis de la obra de Teresa Margolles, en particular de tres de sus exposiciones, cuya información se sistematiza en el cuadro 2.

\begin{tabular}{|c|c|c|c|c|c|}
\hline \multicolumn{6}{|c|}{$\begin{array}{c}\text { Cuadro } 2 \\
\text { Información sobre las obras de Teresa Margolles }\end{array}$} \\
\hline Año & $\begin{array}{l}\text { Nombre } \\
\text { de la obra }\end{array}$ & Curaduría & $\begin{array}{l}\text { Espacio en el que se } \\
\text { presentó }\end{array}$ & Lugar & Patrocinadores \\
\hline 2009 & $\begin{array}{l}\text { ¿De qué } \\
\text { otra cosa } \\
\text { podríamos } \\
\text { hablar? }\end{array}$ & $\begin{array}{l}\text { Cuauhtémoc } \\
\text { Medina }\end{array}$ & $\begin{array}{l}53 \text { Exposición Internacional } \\
\text { de Arte, Bienal de Venecia. } \\
\text { Pabellón Oficial México }\end{array}$ & Italia & $\begin{array}{l}\text { Patronato de Arte } \\
\text { Contemporáneo } \\
\text { A.C. (PAC) }\end{array}$ \\
\hline 2012 & La Promesa & $\begin{array}{l}\text { María Inés } \\
\text { Rodríguez }\end{array}$ & $\begin{array}{l}\text { Museo Universitario de } \\
\text { Arte Contemporáneo } \\
\text { (MUAC), de la Universidad } \\
\text { Nacional Autónoma de } \\
\text { México (UNAM) }\end{array}$ & México & $\begin{array}{l}\text { Alejandro Burillo Az- } \\
\text { cárraga } \\
\text { Juan Carlos del } \\
\text { Valle } \\
\text { Fundación Televisa. } \\
\text { FEMSA }\end{array}$ \\
\hline 2014 & El Testigo & $\begin{array}{l}\text { María Inés } \\
\text { Rodríguez }\end{array}$ & $\begin{array}{l}\text { CA2M } \\
\text { Centro de Arte } 2 \text { de } \\
\text { Mayo Comunidad } \\
\text { de Madrid }\end{array}$ & España & Fundación Ford \\
\hline
\end{tabular}

Fuente: elaboración propia a partir de Margolles (2009; 2012; 2014).

ESCENA. Revista de las artes, 2021, Vol. 80, Núm. 2 (enero-junio), pp. 198-220 
En los siguientes apartados, se presenta una exposición con los ejes centrales de cada una de estas obras.

\section{¿De qué otra cosa podríamos hablar?}

¿De qué otra cosa podríamos hablar? es el nombre de la obra presentada por Teresa Margolles en la 53 Exposición Internacional de Venecia, Italia, en el año 2009. En esta obra, curada por Cuauhtémoc Medina, Margolles representó al Pabellón Oficial de México en el Palacio Roca Ivancich. Esta obra fue patrocinada por el Patronato de Arte Contemporáneo A.C. (PAC), de México (Margolles, 2009). En la obra se presentaron distintas piezas, como: Mesa, un mueble de concreto fabricado con fluidos provenientes de personas asesinadas en México. Limpieza, nombre con el que se conoció la pieza en la que distintos familiares de personas asesinadas en México limpiaron el piso de las salas de exhibición con una mezcla de agua y sangre, proveniente de los cuerpos de sus familiares. Narcomensaje y Bordado, telas impregnadas con la sangre de cuerpos de personas asesinadas en México, las que fueron bordadas con hilos de oro, con los mensajes dejados por el narco. Bandera sumergida, telas teñidas con el color de la sangre que, posteriormente, fueron sumergidas y mezcladas con el agua de mar para presentarlas al público. Finalmente, Intervención Pública con Bandera, una bandera fabricada con un trozo de tela impregnada de sangre, que simbolizaba la bandera mexicana.

En esta obra es posible visualizar lo que Margolles ha denominado una transformación en su estrategia artística, dado que esta artista ha transitado de la fotografía a la morgue, en donde realizó sus primeras obras con el grupo SEMEFO, y de la morgue a las calles, mediante el proceso de recolección de fluidos corporales y sangre de quienes perdieron la vida en el espacio público de ciudades mexicanas. En sus palabras, el nuevo espacio de trabajo es la calle:

Cuando trabajaba con el grupo SEMEFO estaba muy interesada en lo que sucedía dentro de la morgue y las situaciones que ocurrían, digamos, a unos metros afuera de ella, con los familiares, con los deudos. Pero el país ha dado un cambio tan violento que desde la morgue ya no es posible describir lo que está pasando afuera. El dolor, la pérdida y el vacío ya se encuentran en las calles (Margolles, 2009, p. 85). 
De acuerdo con Margolles, este cambio en la estrategia artística refleja una transformación, también, en la producción de la muerte y en la atención y la gestión pública de la muerte producida en estos espacios. Una vez ejecutada la muerte, el acto artístico inicia con Teresa Margolles y una serie de colaboradores que recogen los fluidos y la sangre proveniente de las escenas del crimen. La cita que se reproduce a continuación muestra el procedimiento realizado:

Una vez que es levantado el cuerpo y se han hecho los peritajes propios de la ley, se limpia (entre mis colaboradores y yo) la zona donde hay sangre con telas húmedas. Se absorbe. Después, la tela se seca; una vez seca, se transporta al lugar donde será la exposición y ahí, con el agua local, se vuelve a rehidratar. Con esa mezcla se limpia el piso. La idea comienza con la pregunta ¿quién lava las calles? Cuando es un cuerpo, cuando son tres, cuando son 6.000 personas asesinadas en un año: ¿quién lava los restos que quedan? ¿A dónde se va esta agua?... Ese aglutinado de sangre y lodo (Margolles, 2009, p. 90).

Un último tránsito se da de las calles a la exportación de un arte sobre la muerte al mercado global del arte, que, en este caso, es expuesto en el marco de una bienal, en particular, en la ciudad europea de Venecia. En el marco de esta obra, Margolles presentó Intervención Pública con Bandera, en donde la bandera de los Estados Unidos Mexicanos fue sustituida por un trozo de tela impregnado con la sangre de personas anónimas, quienes habían perdido la vida producto de la violencia vivida en México.

Al retomar las reflexiones planteadas por Graciela Speranza y Georges DidiHuberman, resulta fundamental cuestionarse cuáles son las imágenes que se posicionan en el mercado global del arte sobre lo latinoamericano, en general, y lo mexicano, en particular (Didi-Huberman, 2018; Speranza, 2012). Como se señaló anteriormente, con esta obra Margolles representó al Pabellón Oficial de México en la Bienal de Venecia y su curador, Cuauhtémoc Medina, indicó que la estrategia seguida implicaba una disputa abierta en relación con las imágenes difundidas por el Gobierno mexicano, que trataban de ocultar la violencia y la muerte. De acuerdo con Medina, no hay otro tema de qué hablar en México, por ello, este llega hasta la Bienal de Venecia, con el fin de discutir y enfrentar las imágenes producidas desde los grupos de poder mexicanos. Según sus palabras, la exposición se posiciona frente al imperativo del silencio y surge 
ante la expectativa de las élites mexicanas de que por proteccionismo de la imagen nacional o por sostener las ilusiones del turismo, preferirían que guardáramos un compungido silencio ante la falta de discreción que ha tenido la sociedad de masacrarse ruidosa, voraz y espectacularmente en público (Medina, 2009, p. 29).

Valga señalar que sobre esta idea de lo representado en los mapas (Speranza, 2012), en el catálogo de la obra ¿De qué otra cosa podríamos hablar? se publicó un cuento del prolífico escritor de Sinaloa, Élmer Mendoza, titulado Cada vez que veo un mapa de México se me antoja pintarlo de negro (Mendoza, 2009). En este cuento, que narra la historia de dos cadáveres que van a ser tratados por Teresa Margolles, Mendoza expresa cuál es el arte por producir para ese atlas portátil, que será reconocido en el mercado global del arte:

un arte que la gente no merezca, es lo que quiero, ¿me oyes? Un arte nacido del despojo, de los restos, de lo que queda en la calle después del crimen; reconozco un aroma nuevo que flota en el país, el de la podredumbre extrema y quiero utilizarlo (Mendoza, 2009, p. 111).

\section{La promesa}

La segunda obra analizada en este artículo se titula La Promesa y fue presentada en el Museo Universitario de Arte Contemporáneo (MUAC), de la Universidad Nacional Autónoma de México (UNAM), en el año 2012. Esta obra fue curada por María Inés Rodríguez y contó con el patrocinio de personas particulares, como Alejandro Burillo Azcárraga y Juan Carlos del Valle, y de la Fundación Televisa y FEMSA (Margolles, 2012). La Promesa se ubica en una ciudad mexicana, en Ciudad Juárez, en donde Teresa Margolles ha fotografiado el proceso de expulsión de la ciudad de unas 220 mil personas, quienes han dejado en desuso alrededor de 115 o 120 mil casas. El trabajo se compone de fotografías que dan cuenta del desplazamiento poblacional, al que Margolles denomina "abandono", como se puede leer en el siguiente extracto:

La ciudad en general tiene sectores con casas vacías pero existen zonas que están más desocupadas que otras. Caminando por las calles puedes ver diez casas abandonadas, tres habitadas. No es una ciudad desierta pero en este contexto, ¿qué tipo de relaciones puedes generar? ¿Qué idea de orden, limpieza, armonía, educación se pueden lograr? ¿Cómo explicas o reflexionas con tu familia o tus ami- 
gos, el futuro? (Margolles, 2012, p. 11).

De esta manera, en la obra se presentan una serie de fotografías que muestran casas de habitación individuales y proyectos inmobiliarios desérticos, evidencias tangibles del derrumbe de las promesas realizadas, en primer lugar, en el marco de la entrada en vigencia del Tratado de Libre Comercio de América del Norte (TLCAN), firmado el 1 de enero de 1994. En segundo lugar, estos ofrecimientos se vieron incumplidos por la conflictividad y la violencia desatada en esta región del país. Desde esta perspectiva, la pregunta que Margolles lanza a este proceso es “¿Por qué dejas todo?” (Margolles, 2012, p. 9).

Una vez presentadas las fotografías de Ciudad Juárez, Margolles eligió una casa que fue transportada al Museo Universitario de Arte Contemporáneo (MUAC), de la Universidad Nacional Autónoma de México (UNAM). Margolles realizó la documentación del proceso de desmantelamiento, demolición, transporte y trituración de la casa, que se encuentra documentado en el catálogo de la obra. Cuando la casa fue demolida, la artista construyó una estructura, que fue esparcida por el suelo del MUAC con ayuda de las personas que visitaron el museo durante la ejecución de la obra. Sobre La Promesa, la artista señaló:

¿Qué promesa de bienestar hay en este país? La idea era entender. Sentía que Ciudad Juárez concentraba diversas problemáticas, no solamente el éxodo de la población, sino también la impunidad de los feminicidios, las luchas sociales y la crisis inmobiliaria. La idea de la pieza era comprar una casa, trasladarla a la capital del país y convertirla en polvo, como los cientos de promesas que se han hecho y no se han cumplido (Margolles, 2012, pp. 11-13).

\section{El testigo}

La pieza El Testigo fue presentada en el Centro de Arte 2 de Mayo Comunidad de Madrid, España, en el año 2014. Esta fue curada por María Inés Rodríguez y se compone de cuatro piezas tituladas El Testigo, PM 2010, Esta finca no será demolida y La promesa, obra expuesta anteriormente. El Testigo fue patrocinada por la Fundación Ford (Margolles, 2014). En El Testigo se exponen una serie de fotografías en las que se muestra a aquellos testigos públicos de la violencia vivida en Ciudad Juárez y Culiacán, México. En particular, Margolles presenta como testigos de la violencia a los árboles, en los que quedaron registradas las marcas de las balas y en cuyos pies fueron asesinadas personas. De acuerdo con Margolles, "las marcas de las balas, con los proyectiles dentro de su corteza, son el recuerdo permanente de las personas que han sido asesinadas junto a él” (Margolles, 2014, p. 16). 
Por su parte, PM 2010 es una pieza creada a partir de la recopilación de todas las portadas del medio de comunicación PM, periódico sensacionalista de Ciudad Juárez, que no cuenta con versión digital, solo impresa, y que circula en dicho espacio en competencia con otros medios de comunicación que difunden el mismo tipo de imágenes (Gardea, 2014). Margolles eligió el año 2010 para realizar esta recopilación, dado que en ese año fueron reportados 3700 asesinatos en dicho Estado. En las portadas de este medio destacan las imágenes de cuerpos torturados, asesinatos y ejecuciones, las que se acompañan de mujeres semidesnudas.

En la pieza Esta finca no será demolida se exponen fotografías que documentan el proceso de expulsión y desplazamiento poblacional que llevó al abandono de edificaciones, negocios y casas de habitación en Ciudad Juárez. "Esta finca no será demolida", mensaje que da origen a esta pieza, es la frase que aparece en una casa de habitación, de la que han sido expulsados sus dueños.

En estas tres obras de la artista contemporánea Teresa Margolles es posible identificar una transformación en el foco de sus intereses, observación que es válida para el estudio de estas tres exposiciones. De la obra con sangre y fluidos corporales, propio de ¿De qué otra cosa podríamos hablar?, la artista ha experimentado un tránsito que ahora incluye un trabajo sobre el territorio en el que también se ha expresado la violencia. Proyectos inmobiliarios, negocios, edificaciones de todo tipo, habitaciones y árboles son presentados como los testigos del proceso de expulsión que ha vivido Ciudad Juárez. Estas fotografías dan cuenta de procesos de corte estructural, como el fracaso del modelo económico, la especulación financiera e inmobiliaria, la huida de la vida y la presencia de la muerte. En ese sentido, el trabajo de Margolles posiciona, fundamentalmente, en La Promesa y El Testigo, la forma que adquiere la habitación, la calle y lo público en un escenario de violencia estructural.

\section{Críticas a la obra de Teresa Margolles}

Las críticas a la obra de Teresa Margolles pueden clasificarse en dos tipos. La primera de ellas resalta el carácter abyecto, grotesco y siniestro de su trabajo, el cual daría cuenta de procesos sociales y políticos específicos, como las disputas entre grupos vinculados al narcotráfico y la violencia vivida en México (Barbosa, 2018; Cortés, 2017; Dieguez, 2018; Guerra, 2010; Guevara, 2012; Gutiérrez, 2012; Jiménez, 2010; Speranza, 2012). Speranza (2012), incluso, discute la obra de Teresa Margolles en relación directa con la novela 2666 de Roberto Bolaño, escritor chileño que relató una ficción que se desarrolla en Ciudad Juárez, México, sin nunca haber conocido dicho espacio (Bolaño, 2016). 
Como se observa en la cita que se reproduce a continuación, Guerra valora la producción de Margolles señalando que, en ella, es posible encontrar un proceso de reflexión en torno a la violencia que da cuenta de las conflictividades que se expresan en la calle (Guerra, 2010). Es decir, para este autor la producción estética de Margolles se inscribe en un tipo de arte que problematiza la violencia y la muerte producida en un espacio público, como una de las contradicciones del proyecto moderno. Para Guerra, la obra de Teresa Margolles busca abrir un espacio para la comprensión y la reflexión de la violencia vivida en México, experimentada por todo el cuerpo social. En sus palabras:

La producción artística de lo social ha tenido, y tiene, la misión de visualizar estos conflictos, de exponer los traumas que la violencia extrema deja a su paso. No se trata de aceptar el consenso visual de la muerte, sino de proponer una ontología del desastre y de la vulnerabilidad a la que nos somete el Estado como parte de su estrategia de terror, a su política de supresión y eliminación. Los procedimientos estéticos relacionados con estas premisas ven en la calle el lugar privilegiado para exponer ese cuerpo social violentado, ese estado de excepción en donde unos se convierten en verdugos de otros y donde se expía la culpa por el fracaso de nuestras fallidas e incompletas modernidades (Guerra, 2010, p. 85).

El segundo tipo de críticas, con las que la autora de este artículo se identifica, señalan que la exposición de lo abyecto, lo grotesco y lo siniestro en el arte de Teresa Margolles no necesariamente permite realizar una crítica de la violencia y la muerte, sino una reiteración de estas, dado que también es violenta la estrategia artística de recolección de la materia prima para la realización de este tipo de arte: sangre, partes de cuerpos y cadáveres, que serán exportados a un mercado global. En este caso, destaca la obra de María Campiglia, quien lanza una fuerte crítica a las estrategias seguidas por Teresa Margolles (Campiglia, 2013). En particular, esta autora cuestiona dos aspectos. En primer lugar, la dinámica burocrática e institucional que hace posible que una artista como Margolles obtenga permisos o los logre evadir, para tener acceso a fluidos, tejidos, partes de cuerpos o cadáveres. Desde la perspectiva de Campiglia, un arte como el realizado por Margolles solo es posible en una trama institucional laxa, permisiva y corrupta, como lo es la mexicana. De acuerdo con esta autora,

Trabaja con cadáveres, o con tejido y fluidos procedentes de los mismos, que en algunos casos pertenecen a individuos que han sido asesinados, por lo que se encuentran sujetos a procesos de investigación pericial y su tratamiento debería estar reservado a instancias policiales. Pero es sorprendente que si bien todas estas 
operaciones se hacen públicas no sólo nunca se le ha levantado una demanda o se le ha incautado alguna pieza, sino que siempre ha contado con el cobijo institucional (Campiglia, 2013, p. 113).

En segundo lugar, Campiglia critica las estrategias de producción del arte seguidas por Margolles en cuanto a la consecución de cadáveres de personas de sectores empobrecidos, dado que intercambia partes de cuerpos por ataúdes o rituales funerarios que no pueden ser costeados por las familias de las personas asesinadas, lo que, desde la perspectiva de la autora, convierte a Margolles en una victimaria más de aquellos que han sido víctimas de la violencia producida en México. Como se observa en la siguiente cita, la autora reclama a Margolles el aprovecharse de la condición de vulnerabilidad para donar partes de cuerpos o cadáveres de familiares de quienes no pueden satisfacer esas necesidades.

En estos, como en otros casos en los que ha requerido el permiso de familiares para obtener cuerpos completos, o fragmentos de los mismos, sistemáticamente ha aprovechado el estado de indefensión y extrema pobreza de los deudos, a partir de acuerdos a todas luces insensibles en relación a la situación que estos atravesaban (Campiglia, 2013, p. 116).

De esta forma, desde la perspectiva de Campiglia, el cuerpo de los otros es entendido "simplemente como un objeto más que puede introducirse en la lógica del artemercado" (Campiglia, 2013, p. 119). Esta crítica puede complementarse si se realiza un análisis comparativo con las estrategias seguidas por otras artistas contemporáneas, que, al igual que Teresa Margolles, trabajan en contextos sociohistóricos de profunda violencia y sufrimiento social, como es el caso de la guatemalteca Regina José Galindo (Villena, 2010; 2015). El tratamiento aséptico y forense de una obra como ¿De qué otra cosa podríamos hablar? (Margolles, 2009), así como de exposiciones como Lengua, del año 2000, correspondiente a la exposición de una lengua de un hombre joven que Margolles obtuvo tras el intercambio de un ataúd para las honras fúnebres de su cuerpo, o de Entierro, del año 2004, en donde la artista colocó el cuerpo de un recién nacido fallecido, que su madre otorgó al arte, dado que no tenía recursos para enterrarlo (Campiglia, 2013), muestran un distanciamiento y desapego respecto al dolor social, que no es posible identificar en las performances realizadas por Regina José Galindo.

Pensar los límites del arte de Margolles es, sin duda alguna, pensar también en la relación del arte con la ética (Marques \& Biondi, 2017). Como señala Gutiérrez, más allá del 
espectáculo con la muerte, las preguntas que podríamos hacerle al arte de lo abyecto son: "¿cuál es la dimensión ética y estética de las imágenes de tortura, destrucción, humillación y terror? ¿Cuál es su importancia para la historia y la memoria? ¿Cuál es su dimensión política?" (Gutiérrez, 2012, p. 37). En este caso, la paradoja permisiva del arte contemporáneo consiste en llevar a sus límites la radicalidad del arte, al mostrar fluidos, sangre, partes de cuerpos y cadáveres como piezas de arte, que no necesariamente potencian una crítica radical de las condiciones estructurales que producen esas muertes, ya que el fin último de exportar los restos de cuerpos mutilados es exponerlos como piezas de museo en un mercado globalizado.

\section{Reflexiones finales}

La obra de Teresa Margolles ha sido analizada a partir de las tesis planteadas por Nathalie Heinich $(2002,2017)$, en la cual el paradigma del arte contemporáneo ha permitido el posicionamiento de un arte abyecto, grotesco, siniestro, y en donde la muerte y sus signos ingresan al mercado global del arte y a la institucionalidad que los promueve, como las bienales, las galerías y los museos, sin que necesariamente la producción artística genere mayor reflexión o indignación sobre lo sucedido en México. Las exposiciones individuales y colectivas realizadas por Teresa Margolles dan cuenta del despliegue y el posicionamiento del trabajo de esta artista en un mercado global del arte, mediante el cual ha obtenido financiamiento y reconocimiento global. En los veintitrés años que comprenden el periodo para el cual se tienen datos (1995-2018), se realizaron 278 exposiciones de carácter colectivo y en 67 exposiciones individuales, en las que se trazó un mapa global en donde se dibuja un México particular.

Si bien este es un trabajo que no ha documentado la recepción crítica de la obra de Teresa Margolles, un eje que podría trabajarse posteriormente es cómo la radicalidad de este tipo de propuestas queda opacada al ingresar a un mercado global, fundamentalmente, europeo y estadounidense, espacios en donde la artista ha posicionado su obra, tal y como se expuso en el análisis de los recorridos globales del trabajo de Margolles. De esta manera, la pregunta es si la apertura de límites estéticos del arte, en donde es posible hacer arte con fluidos corporales, sangre, partes de cuerpos y cadáveres, se traduce a una subjetividad y una práctica política solidaria o, al menos, dolida con lo que sucede en México, o simplemente esta se reduce a un acto contemplativo de museo, en donde la radicalidad de la propuesta artística queda cuestionada.

ESCENA. Revista de las artes, 2021, Vol. 80, Núm. 2 (enero-junio), pp. 198-220 
En ese sentido, resulta central indagar y cuestionar la figura del museo, sus producciones artísticas y exposiciones relacionadas con la muerte y con otros procesos sociopolíticos. Cuestionar al museo en donde se exponen como mercancías aquellas artesanías que tuvieron un valor de uso específico (Rivera Cusicanqui \& El Colectivo, 2010), procesos políticos revolucionarios (Didi-Huberman, 2017) o disputas vinculadas a la política de la muerte (Margolles, 2009; 2012; 2014) permite hacer preguntas en torno a la vida y a las subjetividades de los consumidores de dichas imágenes, que se encuentran en otro lugar de la modernidad.

Asimismo, permite preguntar, siguiendo a Pierre Bourdieu, por qué objetos de la vida cotidiana indígena, las insurrecciones o la muerte se institucionalizan y se legitiman en museos europeos, otorgando el reconocimiento a los artistas contemporáneos que los trabajan. De la misma manera, se puede interrogar qué pasa con procesos similares de otros grupos sociales y de otras culturas que no llegan a los museos y, por lo tanto, no obtienen dicho reconocimiento. Siguiendo a Graciela Speranza (2012), estas reflexiones permiten cuestionar si se reconoce a artistas contemporáneas como Teresa Margolles, simplemente, porque aportan este elemento abyecto y siniestro de la vida política mexicana en los circuitos globales del arte contemporáneo, cual contribución exótica de lo latinoamericano y lo mexicano, olvidando las conflictividades de otros países de la región que también han vivido procesos similares.

Ciertamente, la obra de Margolles permite dar cuenta de las dinámicas políticas vividas en México, brindando con ello una mirada a la oscuridad de su época. Sin embargo, al mismo tiempo, no se pueden perder de vista las críticas hechas a su obra, en donde la producción artística puede llegar a ser tan violenta como el proceso que reproduce, tal y como lo ha señalado María Campiglia (2013), lo que da lugar a una serie de cuestionamientos éticos del arte contemporáneo. Finalmente, no se puede negar que el arte contemporáneo forma parte de una paleta de expresiones artísticas, en donde producciones audiovisuales y fenómenos editoriales, con narcocorridos, narconovelas literarias y televisivas, dan cuenta, también, de una transformación en los gustos del público.

\section{Referencias}

Agamben, G. (2011). Desnudez. Barcelona: Anagrama.

Barbosa, A. (2018). La perspectiva artística de la violencia social en México en el último siglo. Panambí, 7, 17-36.

ESCENA. Revista de las artes, 2021, Vol. 80, Núm. 2 (enero-junio), pp.198-220 
Entre el mercado global del arte contemporáneo y

Dossier

la muerte: la obra de Teresa Margolles

Bolaño, R. (2016). 2666. España: Penguin Random House.

Bourdieu, P. (2010). Cuestiones sobre el arte a partir de una escuela de arte cuestionada. En El sentido social del gusto. Elementos para una sociología de la cultura. Siglo XXI Editores.

Bourdieu, P. (2010). Cuestiones sobre el arte a partir de una escuela de arte cuestionada. En El sentido social del gusto. Elementos para una sociología de la cultura (pp. 19-41). Buenos Aires: Siglo XXI Editores.

Campiglia, M. (2013). Teresa Margolles. Reiterar la Violencia. Barcelona, Research, Art, Creation, 2(1), 100-125.

Cortés, A. (2017). Memoria(s) sensible(s): Substancia, cuerpo y rastro en la obra de Rosemberg Sandoval y Teresa Margolles. Ensayos. Historia y teoría del arte, 21(32), 33-43.

Danto, A. (1997). Después del fin del arte. El arte contemporáneo y el linde de la historia. Buenos Aires: Paidós Editorial.

Didi-Huberman, G. (2017). Insurrecciones. Catalunya: Museu Nacional d'Art de Catalunya.

Didi-Huberman, G. (2018). Pueblos expuestos, pueblos figurantes. Argentina: Manantial.

Dieguez, I. (2018). Encarnaciones poéticas. Cuerpo, arte y necropolítica. Athenea Digital. Revista de Pensamiento e Investigación Social, 18(1), 203-219.

Gardea, Ó. (2014). PM / Conflicto e identidad. En El Testigo (pp. 50-61). España: CA2M Centro de Arte 2 de Mayo Comunidad de Madrid.

Geidel, M. (2010). Una mirada desde afuera: explicando el fracaso de una colaboración con Principio Potosí. En S. Rivera Cusicanqui y El Colectivo (eds.), Principio Potosí Reverso (pp. 56-60). Madrid: Museo Reina Sofía.

Guerra, M. (2010). Poderes de la perversión y estética de lo abyecto en el arte latinoamericano. Guaraguo, 34(14), 71-88.

Guevara, C. (2012). La voz del dolor. La violencia entre la estética y la política. En Tiempos oscuros, violencia, arte y cultura. Memoria del IV Encuentro de Investigación y Documentación de Artes Visuales. Consejo Nacional para la Cultura y las Artes.

ESCENA. Revista de las artes, 2021, Vol. 80, Núm. 2 (enero-junio), pp. 198-220 
Gutiérrez, B. (2012). Violencia, espectáculo, arte contemporáneo. En Tiempos oscuros, violencia, arte y cultura. Memoria del IV Encuentro de Investigación y Documentación de Artes Visuales. Consejo Nacional para la Cultura y las Artes.

Heinich, N. (2002). La sociología del arte. Buenos Aires: Ediciones Nueva Visión.

Heinich, N. (2017). El paradigma del arte contemporáneo. Estructuras de una revolución artística. Madrid: Casimiro.

Jiménez, M. (2010). La querella del arte contemporáneo. Buenos Aires: Amorrurtu Editores.

Kilchmann, P. (2018). Biography Teresa Margolles. Galerie Peter Kilchmann. Recuperado de http://www.peterkilchmann.com/files/bio_margolles.pdf

Margolles, T. (2009). ¿De qué otra cosa podríamos hablar? México: Editorial RM.

Margolles, T. (2012). La promesa. México: Museo Universitario Arte Contemporáneo, Universidad Nacional Autónoma de México.

Margolles, T. (2014). El Testigo. España: CA2M Centro de Arte 2 de Mayo Comunidad de Madrid.

Marques, Â. \& Biondi, A. (2017). (In)visibilidade de mulheres sem rosto: Ética e política em imagens fotográficas de Teresa Margolles. Comunicação e Sociedade, 32, 269 - 286.

Medina, C. (2009). Espectralidad materialista. En Teresa Margollas (ed.), ¿De qué otra cosa podríamos hablar? (pp. 15-30). México: Editorial RM.

Mendoza, E. (2009). Cada vez que veo un mapa de México se me antoja pintarlo de negro. En Teresa Margollas (ed.), ¿De qué otra cosa podríamos hablar? (pp. 109112) México: Editorial RM.

Rivera Cusicanqui, S. \& El Colectivo (Eds.). (2010). Principio Potosí Reverso. Madrid: Museo Reina Sofía.

Schwartzberg, E. (2010). Cultura, Patrimonio y Arte. Eufemismos de la cadena colonial. En S. Rivera Cusicanqui y El Colectivo (eds.), Principio Potosí Reverso (pp. 47-53). Madrid: Museo Reina Sofía. 
Entre el mercado global del arte contemporáneo y

la muerte: la obra de Teresa Margolles

Speranza, G. (2012). Atlas portátil de América Latina. Arte y ficciones errantes. BarceIona: Editorial Anagrama.

Villena, S. (2010). Regina Galindo: El arte de arañar el caos del mundo. El performance como acto de resistencia. Revista Centroamericana de Ciencias Sociales, 7, 49-78.

Villena, S. (2015). El anti-ceremonial público en la obra de Regina José Galindo. Revista de Estudios Globales y Arte Contemporáneo, 3(1), 172-197. 